\title{
An Evaluation of Excellence in Primary Healthcare Units After Introduction of a Performance Management Innovation in Two Regional States of Ethiopia: A Facility Based Comparative Study
}

\author{
Wubishet Kebede Heyi \\ JSI Research \& Training Institute, Inc. in Ethiopia \\ Elias Mamo Gurmamo \\ JSI Research \& Training Institute, Inc. in Ethiopia \\ Amare Assefa Arena \\ JSI Research \& Training Institute, Inc. in Ethiopia \\ Agegnehu Gebru Sendeku \\ JSI Research \& Training Institute, Inc. in Ethiopia \\ Abera Refissa \\ JSI Research \& Training Institute, Inc. in Ethiopia \\ Feyissa Serbesa \\ JSI Research \& Training Institute, Inc. in Ethiopia \\ Mesele Argaw ( $\nabla$ mdamte5@gmail.com ) \\ JSI Research \& Training Institute, Inc. in Ethiopia \\ Binyam Fekadu Desta \\ JSI Research \& Training Institute, Inc. in Ethiopia
}

\section{Research Article}

Keywords: performance management, organizational culture, primary healthcare unit, excellence, Ethiopia

Posted Date: November 1st, 2021

DOI: https://doi.org/10.21203/rs.3.rs-1016072/v1

License: @ (i) This work is licensed under a Creative Commons Attribution 4.0 International License. Read Full License

Version of Record: A version of this preprint was published at BMC Health Services Research on April 8th, 2022. See the published version at https://doi.org/10.1186/s12913-022-07885-8. 


\section{Abstract Background}

The Ethiopian Ministry of Health strives to achieve universal health coverage (UHC) through increasing the number of its high-performing primary healthcare units. Although the Ethiopian health system is managed within a decentralized political system, the Ministry of Health works towards institutionalizing performance management innovations and organizational cultures that increase the excellence of primary healthcare entities. To date, there has been little evidence gathered on the factors influencing the excellence of primary healthcare units in Ethiopia. Therefore, the aim of this study was to assess and compare how the introduction of performance management and organizational culture innovations through project support affect the excellence of primary healthcare units in Ethiopia.

\section{Methods}

A facility-based comparative study was conducted in USAID Transform: Primary Health Care project supported, and non-supported primary healthcare units located in the Oromia and Southern Nations Nationalities and Peoples' (SNNP) regions of Ethiopia. Quantitative data were collected from randomly selected health workers using interviewer-administered questionnaires. In addition, primary healthcare unit excellence measurements were extracted from routine health information databases over eight quarters. The data were analyzed using the Statistical Package for Social Science (SPSS IBM v 20) research software package. Results were presented in frequency tables and graphs. After checking the data for homogeneous distribution, a paired sample t-test for equal variances otherwise a Mann-Whitney $U$ test was analyzed to claim statistically significant difference at $P<0.05$.

\section{Results}

Out of 368 invited health workers, 364 (a response rate of 98.9\%) participated in this study. Slightly higher than two-thirds of participants were enrolled from the Jimma Zone of Oromia Region. Orientations on performance management standards were provided to 101 (68.2\%) and 45 (48.3\%) health workers from project-supported and non-supported facilities, respectively. The mean perceived organizational culture score with [ \pm Standard Deviation (SD)] was $3.72 \pm 0.75$ among project-supported health workers and $3.385 \pm 0.75$ among non-supported health workers, respectively. An independent sample t-test showed statistically significant differences, where project-supported health workers had higher mean scores on perceived organizational culture than their nonsupported counterparts, with $t=433, d f=362, P=0.001$. The mean baseline primary healthcare unit excellence score was $63.2 \%$ and $50.5 \%$ for project-supported and non-supported health facilities, respectively. The end line excellence scores were increased to $93.3 \%$ for project-supported and $79.1 \%$ for non-supported facilities. The end line overall primary healthcare units' mean rank excellence scores were 257.67 for the project supported and 105.66 for non-project supported facilities. This result of a non-parametric test called the Mann-Whitney $\mathrm{U}$ test revealed that project-supported facilities were higher and had a positive statistically significant difference $(U=2,728, z=-13.78, P=0.001)$.

\section{Conclusions}

The findings of this study underscore a direct relationship between implementing performance management innovations and enhancing organizational cultures with excellence at primary healthcare units. Project-supported primary healthcare units had a higher organizational culture and excellence scores than their counterpart non-supported facilities. Therefore, achieving UHC through excellence in primary healthcare facilities requires scaling up of performance management innovation interventions.

\section{Introduction}

In the last two decades, the world has witnessed remarkable improvements in health, particularly in many low-income countries, towards ensuring availability of accessible, equitable, and quality essential healthcare to populations [1]. Despite these improvements, in low-income countries, significantly high number of mothers, neonates and children are dying due to preventable causes. Hence, as part of the Sustainable Development Goals (SDGs), 180 countries have committed to further reducing these deaths. According to the SDG pledges, by the year 2030, five of the seventeen SDGs will contribute to better health outcomes through strategic implementation of innovations that enhance good health and wellbeing for people, ensure quality education, expand decent work and economic growth, and further reduce inequalities [2].

The ability of a country to meet its goals depends largely on its existing performance management practices, organizational culture, and a high performing primary healthcare entity [3]. An organization's culture defines the agreed norms within the organization. It is characterized by employees' perceptions and behavior in an organization [4]. Well-functioning health leaders develop and shape subordinates through sharing values, beliefs, and assumptions [5]. Building organizational culture needs continuous effort and innovations [6].

The Ethiopian Health Sector Transformation Plan (2020- 2025) strategizes to achieve five major agendas, namely: quality and equity, information revolution, motivated competent and compassionate health workforce, health financing, and leadership [5]. The Ministry implements the Ethiopian Health Center Reform Implementation Guidelines (EHCRIGs) as minimum standards that categorize primary healthcare unit excellence [7]. EHCRIGs are expected to be implemented in all health centers in Ethiopia. Development partners also provide technical and financial support through promoting commitment, responsiveness and accountability at primary health care level. 
USAID Transform: Primary Health Care project institutionalizes performance management innovations [8]. It strives to improve work environment and management systems through building visible leadership, enhancing culture of quality, availing client focus services, and exercising transparency and accountability in the health system. The project supports the health system on the cyclic implementation of performance management initiatives within the primary healthcare entities. In addition, placing performance management dimensions at the center, its technical support has four clustered components which consist of: (1) introducing minimum standards, (2) performance measurement, (3) developing quality and performance improvement projects, and (4) reporting on progress. This is because performance management innovations help the health system to enhance organizational culture and achieve organizational excellence [9].

There is empirical evidence of the influence of organizational culture and its four traits: involvement, consistency, adaptability, and mission on higher performances of several business entities [3] [6] [10]. Currently, there is no clear information on the contribution of performance management innovations on building organizational culture and primary healthcare unit excellence in Ethiopia. Therefore, this study aimed to compare the influence of performance management innovations on building organizational culture and primary healthcare unit excellence in Ethiopia.

In the last two decades, the world has witnessed remarkable improvements in health, particularly in many low-income countries, towards ensuring availability of accessible, equitable, and quality essential healthcare to populations [1]. Despite these improvements, in low-income countries, significantly high number of mothers, neonates and children are dying due to preventable causes. Hence, as part of the Sustainable Development Goals (SDGs), 180 countries have committed to further reducing these deaths. According to the SDG pledges, by the year 2030, five of the seventeen SDGs will contribute to better health outcomes through strategic implementation of innovations that enhance good health and wellbeing for people, ensure quality education, expand decent work and economic growth, and further reduce inequalities [2].

The ability of a country to meet its goals depends largely on its existing performance management practices, organizational culture, and a high performing primary healthcare entity [3]. An organization's culture defines the agreed norms within the organization. It is characterized by employees' perceptions and behavior in an organization [4]. Well-functioning health leaders develop and shape subordinates through sharing values, beliefs, and assumptions [5]. Building organizational culture needs continuous effort and innovations [6].

The Ethiopian Health Sector Transformation Plan (2020- 2025) strategizes to achieve five major agendas, namely: quality and equity, information revolution, motivated competent and compassionate health workforce, health financing, and leadership [5]. The Ministry implements the Ethiopian Health Center Reform Implementation Guidelines (EHCRIGs) as minimum standards that categorize primary healthcare unit excellence [7]. EHCRIGs are expected to be implemented in all health centers in Ethiopia. Development partners also provide technical and financial support through promoting commitment, responsiveness and accountability at primary health care level.

USAID Transform: Primary Health Care project institutionalizes performance management innovations [8]. It strives to improve work environment and management systems through building visible leadership, enhancing culture of quality, availing client focus services, and exercising transparency and accountability in the health system. The project supports the health system on the cyclic implementation of performance management initiatives within the primary healthcare entities. In addition, placing performance management dimensions at the center, its technical support has four clustered components which consist of: (1) introducing minimum standards, (2) performance measurement, (3) developing quality and performance improvement projects, and (4) reporting on progress. This is because performance management innovations help the health system to enhance organizational culture and achieve organizational excellence [9].

There is empirical evidence of the influence of organizational culture and its four traits: involvement, consistency, adaptability, and mission on higher performances of several business entities [3] [6] [10]. Currently, there is no clear information on the contribution of performance management innovations on building organizational culture and primary healthcare unit excellence in Ethiopia. Therefore, this study aimed to compare the influence of performance management innovations on building organizational culture and primary healthcare unit excellence in Ethiopia.

\section{Operational definitions}

Involvement: is an internal organizational factor in developing organizational culture and is signified by transparent communication, employee-focused leadership, and strong interpersonal relationships within the organization [10].

Consistency: is an internal organizational factor in developing organizational culture and refers to the level of cohesion, integration, or agreement around values and norms [10].

Adaptation: is an external factor in maintaining an organizational culture that reflects an evolutionary approach to organizational culture and suggests that cultures develop and persist because they help an organization to survive and flourish [10].

Mission: is an external factor in maintaining an organizational culture that provides purpose and meaning by defining a social role and external goals for the organization [10].

Performance management innovation: includes team-based training of health workers on minimum standards, use of data for decision making, and strategic problem-solving tools. In addition, the project assigned health systems strengthening expert who closely provided technical support on continuous measurement of performances, development of do-able projects, and organization of experience sharing events and performance review meetings [4] [9].

\section{Methods And Materials}




\section{Study setting}

In the last three decades, Ethiopia has endorsed a health policy, with the principles of decentralization and devolution of power to the district level [11]. A district is formed with a population of 60,000 to 100,000 , which is empowered to manage sector offices including four to five primary healthcare units. The primary level of care is comprised of health centers that serve 15,000 to 25,000 people and which manage, on average, five satellite health posts, each serving 3,500 to 5,000 people [5].

USAID Transform: Primary Health Care has been supporting 1,843 health centers under 443 districts located in five regions, namely: Tigray, Amhara, Oromia, Sidama, and SNNP. Jimma is an administrative zone within the Oromia Region and is 360 kilometers southwest of Addis Ababa, the capital city of Ethiopia. The zone has a population of 3,598,359 living in 22 districts with 104 health centers. Out of these, 11 districts and 72 primary healthcare units have been receiving performance management innovation support. Similarly, Kembata Tembaro Zone has a population of 969,160 living in 11 districts with 31 primary health care units. Of these, five districts and 17 primary healthcare units have been receiving innovative performance management interventions [8].

\section{Study design and period}

A facility-based comparative study was conducted to investigate primary healthcare units' excellence between project-supported and non-supported facilities after implementing performance management innovation interventions for about two years. This study was conducted from 25 February 2021 to 30 April 2021.

\section{Analytical framework}

For this study, a modified conceptual model was adopted from Public Health Foundation's performance management and Denison's organizational culture frameworks (Fig. 1) [10] [12]. The framework assumes that good performance management practices can lead to building an organizational culture. Organizational culture was assessed using its four dimensions, namely: involvement, consistency, adaptability, and mission. In addition, organizational excellence is the result of an organization's culture and performance management practices. To show the relationship among performance management innovation, organizational culture, and primary healthcare unit excellence, a logical flow of events best fits the process of descriptive and inferential statistical analysis. The first and second steps measured the perceived performance management innovation activities and traits of organizational culture through the participation of staff. The third step is to extract and transform organizational excellence measurement data to categorize primary healthcare entities into three, namely: low-, medium-, and high-performance statuses.

\section{Source population and sampled population}

The first target population for this study was all primary healthcare units located in Jimma and Kembata Temabro administrative zones of Ethiopia. The second target population was the health workforce serving in primary healthcare units. The sampled health workers' educational backgrounds include health officers, nurses, midwives, laboratory technologists, pharmacists, and business management.

\section{Variables under study}

Dependent variable: the overall score of primary healthcare units' excellence (the average scores of 10 chapters, 87 standards, and 209 validation criteria of EHCRIGs). Rated from $0.0 \%$ to $100.0 \%$.

Independent variables: performance management and organizational culture scores.

\section{Sample size and sampling procedures}

The required sample size for this study was estimated by using a double population proportion formula: $\mathrm{n}=(Z \mathrm{a} / 2+Z \beta) 2$ * $(\mathrm{p} 1(1-\mathrm{p} 1)+\mathrm{p} 2(1-\mathrm{p} 2)) /(\mathrm{p} 1-\mathrm{p} 2) 2$.

Where, $Z a / 2$ is the critical value of the normal distribution at $\alpha / 2$ (i.e. confidence level of $95 \%, a$ is 0.05 and the critical value is 1.96 ), $Z \beta$ is the critical value of the normal distribution at $\beta$ (i.e. for a power of $80 \%, \beta$ is 0.2 and the critical value is 0.84 ), p1 is $50 \%$ of primary healthcare units excellence score for nonproject supported entities, and p2 is $65 \%$ for the project supported primary healthcare units. The level of statistical significance is $0.05, \beta=$ type II error 0.2 , and the non-response rate $10 \%$. In this study, a total of 368 primary healthcare workers, that is, 184 from project-supported and 184 from non-supported primary healthcare units were sampled. The USAID Transform: Primary Health Care project implemented performance management innovations in Jimma and Kembta Tembaro administrative zones. Therefore, both zones were selected purposefully. However, research participants were enrolled using systematic random sampling methods.

\section{Data collection tools, procedure, and data quality assurance methods}

Several tools were used to collect data required to address the objectives of the study. A structured questionnaire was employed to collect data to measure performance management practices and organizational culture. In addition, pretested data abstraction forms were used to collect primary healthcare unit excellence scores from a routine health information system database.

\section{Data quality assurance methods}

As part of ensuring the quality of collected data, the investigators adopted pretested organizational culture [10], performance management, and primary healthcare unit excellence measurement tools [7] and inputs were gathered from other similar studies [13] [14]. In addition, the data collectors were six public health officers who were trained and deployed to collect the required data in 38 primary healthcare units. Completeness and consistency of information were checked on the date of data collection.

Data analysis 
The data was entered and analyzed using SPSS version 25 [15]. A descriptive analysis was used to present the summary of the data using graphs and frequency tables. To determine the magnitude of performance management, 24 close-ended questions were scored with a " 1 " for positive and a "0" for a negative response. The overall performance management score was rated out of 24 . To check the presence of statistical differences for categorical variables, a chi-square test was analyzed and a $\mathrm{P}<0.05$ was the decision criteria.

To estimate the organizational culture, 34 five-point Likert scale questions were rated by the participants. The organizational culture assessment tool has four sub-categories, namely: involvement (9 questions), consistency (8 questions), adaptability (8 questions), and mission (9 questions). The reliability test was determined using Cronbach's alpha values and the results were 0.900 for involvement, 0.716 for consistency, 0.865 for adaptability, 0.916 for the mission, and 0.946 for the overall organizational culture. Therefore, the tool used to demonstrate organizational culture was consistent and reliable. An independent sample t-test was analyzed for homogeneous (Levene's Test $>0.05$ ) continuous variables and statistical significance was claimed at $P<0.05$.

Excellence at primary healthcare units was assessed using minimum standards of EHCRIGs [7][13][14] which has10 chapters and 87 sets of minimum standards with 209 validation criteria. Primary health care unit excellence was measured out of 100 percentage points and categorized into three: high performing primary healthcare units' (excellence) for scores greater or equal to $80.0 \%$, medium performing for scores between $60.0 \%$ and $79.9 \%$, and low performing for scores less than $60.0 \%$ [7]. The two-sample primary healthcare unit excellence measurement data violate the assumptions of a parametric test (Levene's test < 0.05). The investigators compared the mean rank differences between project-supported and non-supported facilities using a non-parametric statistical test called the Mann-Whitney U test.

\section{Ethical considerations}

This study was granted an ethical clearance from the JSI Research \& Training Institute, Inc. institutional review board (IRB) ref number IRB \#21-06E. Permission to conduct individual interviews was sought from facility managers. Informed written individual consent was taken from each study participant. The investigators maintained national and international ethical principles, including ensuring anonymity and confidentiality.

\section{Results}

Table 1 depicts the socio-demographic characteristics of the study participants. The questionnaires were completed by 184 (100.0\%) and 180 ( $97.8 \%$ ) of participants recruited from project-supported and non-supported primary healthcare units, respectively. Thus, the overall response rate of this study was 364 (98.9\%). Slightly higher than two-thirds of the study participants were enrolled from within the Oromia Region and three-fourth of the health workers were enrolled from rural primary healthcare units. The descriptive analysis ensured that project-supported and non-supported health workers had no statistically different distribution $(P>0.05)$. 
Table 1

Socio-demographic characteristics of the research participants, August 2021

\begin{tabular}{|c|c|c|c|c|c|c|c|c|}
\hline \multirow[t]{3}{*}{ Variable } & \multirow[t]{3}{*}{ Category } & \multicolumn{5}{|c|}{ Health Center Reform Guidelines Implementation } & \multirow{2}{*}{\multicolumn{2}{|c|}{$\begin{array}{l}\text { Total } \\
\mathrm{N}=364\end{array}$}} \\
\hline & & \multicolumn{2}{|c|}{ Project supported $(\mathrm{N}=184)$} & \multicolumn{2}{|c|}{ Non project supported $(\mathrm{N}=180)$} & \multirow[t]{2}{*}{ P-value } & & \\
\hline & & Frequency & Percent & Frequency & Percent & & Frequency & Percent \\
\hline \multirow[t]{2}{*}{ Region } & Oromia & 125 & $67.9 \%$ & 120 & $66.7 \%$ & 0.797 & 245 & $67.3 \%$ \\
\hline & SNNP & 59 & $32.1 \%$ & 60 & $33.3 \%$ & & 119 & $32.7 \%$ \\
\hline \multirow[t]{2}{*}{ Sex } & Male & 121 & $65.8 \%$ & 124 & $68.9 \%$ & 0.525 & 245 & $67.0 \%$ \\
\hline & Female & 63 & $34.2 \%$ & 56 & $31.1 \%$ & & 119 & $33.0 \%$ \\
\hline \multirow[t]{2}{*}{ Address } & Rural & 133 & $72.3 \%$ & 141 & $78.3 \%$ & 0.181 & 274 & $75.0 \%$ \\
\hline & Urban & 51 & $27.7 \%$ & 39 & $21.7 \%$ & & 90 & $25.0 \%$ \\
\hline \multirow[t]{4}{*}{ Age } & $<26$ years & 48 & $26.0 \%$ & 54 & $30.0 \%$ & 0.453 & 102 & $28.0 \%$ \\
\hline & $26-30$ years & 91 & $49.5 \%$ & 74 & $41.1 \%$ & & 165 & $45.3 \%$ \\
\hline & 31 - 35 years & 31 & $16.8 \%$ & 37 & $20.6 \%$ & & 68 & $18.7 \%$ \\
\hline & $36+$ years & 14 & $7.6 \%$ & 15 & $8.3 \%$ & & 29 & $8.0 \%$ \\
\hline \multirow[t]{8}{*}{ Profession } & BSc public health officer & 47 & $25.5 \%$ & 34 & $18.9 \%$ & 0.672 & 81 & $22.3 \%$ \\
\hline & Diploma nurse & 44 & $23.9 \%$ & 46 & $25.6 \%$ & & 90 & $24.7 \%$ \\
\hline & BSc nurse & 23 & $12.5 \%$ & 33 & $18.3 \%$ & & 56 & $15.4 \%$ \\
\hline & Management (diploma and BA) & 21 & $11.4 \%$ & 25 & $13.9 \%$ & & 46 & 12.6 \\
\hline & Midwife (BSc and diploma) & 19 & $10.3 \%$ & 16 & $8.9 \%$ & & 35 & $9.6 \%$ \\
\hline & BSc Pharmacy & 13 & $7.0 \%$ & 12 & $6.7 \%$ & & 25 & $6.8 \%$ \\
\hline & BSc Laboratory technologist & 10 & $5.4 \%$ & 9 & $5.0 \%$ & & 19 & $5.2 \%$ \\
\hline & Health information technician & 7 & $3.8 \%$ & 5 & $2.8 \%$ & & 12 & $3.3 \%$ \\
\hline \multirow[t]{3}{*}{ Marital status } & Single & 99 & $53.8 \%$ & 92 & $51.1 \%$ & 0.876 & 191 & $52.7 \%$ \\
\hline & Married & 84 & $45.7 \%$ & 87 & $48.3 \%$ & & 171 & $46.9 \%$ \\
\hline & Separated /divorced & 1 & $0.5 \%$ & 1 & $0.6 \%$ & & 2 & $0.5 \%$ \\
\hline \multirow[t]{3}{*}{ Years of service } & $<6$ years & 81 & $44.0 \%$ & 80 & $44.4 \%$ & 0.619 & 161 & $44.2 \%$ \\
\hline & $6-15$ years & 100 & $54.4 \%$ & 98 & $54.5 \%$ & & 198 & $54.4 \%$ \\
\hline & $16+$ years & 3 & $1.6 \%$ & 2 & $1.1 \%$ & & 5 & $1.4 \%$ \\
\hline
\end{tabular}

\section{Performance Management}

Table 2 presents the performance management practices using four major categories. Orientations on the minimum primary healthcare unit excellence standards (EHCRIGs) were provided to staff working in 101 (68.2\%) project supported and 45 (48.3\%) and non-project supported facilities. 98 (71.5\%) of staff from project-supported facilities participated in the measurement of governance and management-related minimum standards while 70 (60.9\%) of staff from non-project-supported facilities were actively engaged in governance and management standards measurements. 
Table 2

Performance management practices of project and non-project supported facilities, August 2021

\begin{tabular}{|c|c|c|c|c|c|c|c|}
\hline \multirow[t]{3}{*}{ Variable } & \multirow[t]{3}{*}{ Category } & \multicolumn{4}{|c|}{ Performance management } & \multirow[t]{3}{*}{$x^{2}$} & \multirow{3}{*}{$\begin{array}{l}\mathrm{P}- \\
\text { value }\end{array}$} \\
\hline & & \multicolumn{2}{|c|}{$\begin{array}{l}\text { Project supported } \\
(\mathrm{N}=184)\end{array}$} & \multicolumn{2}{|c|}{$\begin{array}{l}\text { Non-project supported } \\
(\mathrm{N}=180)\end{array}$} & & \\
\hline & & $\mathrm{N}$ & $\%$ & $\mathrm{~N}$ & $\%$ & & \\
\hline \multirow{4}{*}{$\begin{array}{l}\text { Performance standard } \\
(\mathrm{n} 1=148 \& \mathrm{n} 2=116)\end{array}$} & Onsite and off-site training & 89 & $60.1 \%$ & 42 & $36.21 \%$ & 14.89 & 0.001 \\
\hline & Orientation in staff meetings & 101 & $68.2 \%$ & 56 & $48.3 \%$ & 10.75 & 0.001 \\
\hline & Self-study (reading guidelines) & 50 & $33.8 \%$ & 44 & $37.9 \%$ & 0.48 & 0.485 \\
\hline & Self-study (reading posters \& job aids) & 45 & $30.4 \%$ & 52 & $44.8 \%$ & 5.82 & 0.016 \\
\hline \multirow{6}{*}{$\begin{array}{l}\text { Performance Measurement } \\
(n 1=137 \& n 2=115)\end{array}$} & Governance/management & 98 & $71.5 \%$ & 70 & $60.9 \%$ & 3.19 & 0.074 \\
\hline & Drugs and therapeutics & 68 & $49.6 \%$ & 38 & $33.0 \%$ & 7.06 & 0.008 \\
\hline & Clean and safe health facility & 66 & $48.2 \%$ & 52 & $45.2 \%$ & 0.22 & 0.639 \\
\hline & Infection prevention & 49 & $35.8 \%$ & 34 & $29.6 \%$ & 1.08 & 0.297 \\
\hline & Quality/performance management & 51 & $37.2 \%$ & 31 & $27.0 \%$ & 3.00 & 0.083 \\
\hline & Medical equipment management & 35 & $25.5 \%$ & 20 & $17.4 \%$ & 2.43 & 0.118 \\
\hline \multirow{11}{*}{$\begin{array}{l}\text { Performance Improvement ( } \mathrm{n} 1=184 \& \\
\mathrm{n} 2=180)\end{array}$} & Antenatal care & 103 & $56.0 \%$ & 80 & $44.4 \%$ & 4.84 & 0.028 \\
\hline & Skilled birth attendance & 102 & $55.4 \%$ & 85 & $47.2 \%$ & 2.45 & 0.117 \\
\hline & Family planning & 98 & $53.3 \%$ & 78 & $43.3 \%$ & 3.59 & 0.058 \\
\hline & Postnatal care & 96 & $52.2 \%$ & 67 & $37.2 \%$ & 8.22 & 0.004 \\
\hline & Growth monitoring & 88 & $47.8 \%$ & 58 & $32.2 \%$ & 9.22 & 0.002 \\
\hline & Clean and safe health facility & 89 & $48.4 \%$ & 55 & $30.6 \%$ & 12.07 & 0.001 \\
\hline & Community-based health insurance & 85 & $46.2 \%$ & 52 & $28.9 \%$ & 11.61 & 0.001 \\
\hline & Health center-health post linkage & 71 & $38.6 \%$ & 50 & $27.8 \%$ & 4.79 & 0.029 \\
\hline & Laboratory services & 70 & $38.0 \%$ & 40 & $22.2 \%$ & 10.8 & 0.001 \\
\hline & Pharmacy services & 68 & $37.0 \%$ & 39 & $21.7 \%$ & 10.24 & 0.001 \\
\hline & Health information management & 13 & $7.1 \%$ & 47 & $26.1 \%$ & 23.97 & 0.001 \\
\hline \multirow[t]{3}{*}{ Reporting progress } & Reviewed reports & 150 & $81.5 \%$ & 115 & $63.9 \%$ & 23.32 & 0.001 \\
\hline & Data used for performance appraisals & 115 & $62.5 \%$ & 75 & $41.7 \%$ & 15,82 & 0.001 \\
\hline & $\begin{array}{l}\text { Experiences shared through alliance } \\
\text { for quality }\end{array}$ & 104 & $56.5 \%$ & 64 & $35.6 \%$ & 16.09 & 0.001 \\
\hline
\end{tabular}

\section{Perceived organizational culture}

The mean overall perceived organizational culture score with [ \pm Standard Deviation (SD)] was $3.72 \pm 0.75$ and $3.38 \pm 0.7$, for respondents from project and non-project supported facilities, respectively. After ensuring the assumption of homogeneity of the data set using Levene's Test $>0.05$, an independent sample t-test was analyzed. The organizational culture score was statistically higher among respondents working in project-supported rather than non-projectsupported facilities, at $t=433, d f=362, p=0.001$ (Table 3 ). 
Table 3

Comparing average organization culture scores against project support status, August 2021

\begin{tabular}{|c|c|c|c|c|c|c|}
\hline \multirow[t]{2}{*}{ Indicators } & \multicolumn{2}{|c|}{$\begin{array}{l}\text { Project supported } \\
(\mathrm{N}=184)\end{array}$} & \multicolumn{2}{|c|}{$\begin{array}{l}\text { Non-project supported } \\
(\mathrm{N}=180)\end{array}$} & \multirow[t]{2}{*}{ t-test } & \multirow[t]{2}{*}{ P-value } \\
\hline & Mean & SD & Mean & SD & & \\
\hline Empowerment & 3.74 & 1.01 & 3.30 & 1.05 & 4.04 & 0.001 \\
\hline Team orientation & 3.79 & 0.89 & 3.46 & 0.88 & 3.50 & 0.001 \\
\hline Capability development & 3.76 & 0.91 & 3.41 & 1.03 & 3.43 & 0.001 \\
\hline Involvement & 3.76 & 0.82 & 3.39 & 0.82 & 4.32 & 0.001 \\
\hline Core values & 3.77 & 0.83 & 3.51 & 0.93 & 2.80 & 0.001 \\
\hline Agreement & 3.66 & 0.94 & 3.23 & 0.97 & 4.23 & 0.001 \\
\hline Coordination and integration & 3.78 & 1.83 & 3.15 & 1.09 & 3.92 & 0.001 \\
\hline Consistency & 3.75 & 1.00 & 3.31 & 0.85 & 4.47 & 0.001 \\
\hline Creating change & 3.57 & 0.95 & 3.30 & 1.09 & 2.52 & 0.012 \\
\hline Customer focus & 3.69 & 0.89 & 3.37 & 0.96 & 3.30 & 0.001 \\
\hline Organizational learning & 3.54 & 0.96 & 3.24 & 0.87 & 3.09 & 0.002 \\
\hline Adaptability & 3.40 & 0.82 & 3.30 & 0.82 & 3.44 & 0.001 \\
\hline Strategic direction and intent & 3.83 & 0.83 & 3.58 & 0.90 & 2.74 & 0.006 \\
\hline Goals and objectives & 3.67 & 0.89 & 3.48 & 0.83 & 2.11 & 0.035 \\
\hline Vision & 3.76 & 0.88 & 3.48 & 0.92 & 2.95 & 0.003 \\
\hline Mission & 3.75 & 0.80 & 3.51 & 0.77 & 2.93 & 0.004 \\
\hline Overall organizational culture & 3.72 & 0.75 & 3.38 & 0.71 & 4.33 & 0.001 \\
\hline
\end{tabular}

\section{Excellence at primary healthcare units}

Table 4 presents quarterly excellence scores of primary health care units in three categories. At the first measurement, 1 (5.0\% ) project-supported facility had achieved a score of excellence. This score shows an increasing trend, and all project-supported facilities achieved the measurement criteria at the seventh measurement. Conversely, 1 (5.5\%) and 12 (66.6\%) of facilities from non-project supported facilities achieved excellence scores against the criteria at fourth and eighth measurements, respectively. Figure 2 depicts trends in excellence scores of primary health care units against measurement criteria and status of project support. During the first measurement, the overall EHCRIG score was $63.2 \%$ and $50.5 \%$ for project and non-project supported facilities. The subsequent scores showed an increasing trend between both groups of facilities. At the fourth measurement, project-supported facilities achieved the minimum criteria for primary health care unit excellence (EHCRIGs score=80.4\%), while non-project-supported facilities achieved the minimum standards $($ EHCRIG score=79.1\%) at the eighth quarter of measurements.

Table 4

Excellence scores of primary health care units in three categories, August 2021

\begin{tabular}{|c|c|c|c|c|c|c|c|c|c|c|c|c|c|c|c|}
\hline \multirow{2}{*}{$\begin{array}{l}\text { Excellence } \\
\text { criteria }\end{array}$} & \multicolumn{2}{|l|}{ QI } & \multicolumn{2}{|l|}{ Q II } & \multicolumn{2}{|l|}{ Q III } & \multicolumn{2}{|l|}{ Q IV } & \multicolumn{2}{|l|}{ Q V } & \multicolumn{2}{|l|}{ Q VI } & \multicolumn{2}{|c|}{ Q VII } & \multirow[b]{2}{*}{$\mathrm{Pr}$} \\
\hline & Project & $\begin{array}{l}\text { Non- } \\
\text { project }\end{array}$ & Projec & $\begin{array}{l}\text { Non- } \\
\text { project }\end{array}$ & Projec & $\begin{array}{l}\text { Non- } \\
\text { project }\end{array}$ & Projec & $\begin{array}{l}\text { Non- } \\
\text { project }\end{array}$ & Projec & $\begin{array}{l}\text { Non- } \\
\text { project }\end{array}$ & Projec & $\begin{array}{l}\text { Non- } \\
\text { project }\end{array}$ & Projec & $\begin{array}{l}\text { Non- } \\
\text { project }\end{array}$ & \\
\hline$<60 \%$ & 9 & 15 & 4 & 8 & 2 & 5 & 0 & 1 & 0 & 2 & 0 & 1 & 0 & 1 & 0 \\
\hline $\begin{array}{l}60 \%- \\
79.9 \%\end{array}$ & 10 & 3 & 8 & 10 & 8 & 13 & 9 & 15 & 5 & 15 & 4 & 13 & 0 & 9 & 0 \\
\hline $80 \%+$ & 1 & 0 & 8 & 0 & 10 & 0 & 11 & 2 & 15 & 1 & 16 & 4 & 20 & 8 & 20 \\
\hline Total & 20 & 18 & 20 & 18 & 20 & 18 & 20 & 18 & 20 & 18 & 20 & 18 & 20 & 18 & 20 \\
\hline
\end{tabular}

The data collected on primary healthcare unit excellence violates the assumption of the equality of variance, (Levene's test $F=8.49, P<0.004 ; F=19.63, P<0.001$; $\mathrm{F}=25.81, \mathrm{P}<0.001)$ on all three of EHCRIGs measurements. The investigators analyzed the mean rank scores between project and non-project supported facilities using a non-parametric test named the Mann-Whitney $U$ test (Table 5). The results of the first measurements showed that the overall primary healthcare units' mean rank excellence score was 216.87 for project and 147.37 for non-project supported facilities $(U=10,236.50, Z=-6.30, P=0.001)$. Similarly, 
the results of the eighth measurements revealed statistically different overall primary healthcare unit excellence mean rank scores of 257.67 for project and 105.66 for non-project supported facilities $(U=2,728, z=-13.78, p=0.001)$.

Table 5

Primary health unit excellence scores mean rank test using Mann-Whitney U Test, August 2021

\begin{tabular}{|llllll|}
\hline & EHCRIG (Q1) & \multicolumn{3}{c|}{ EHCRIG (Q4) } & \multicolumn{1}{c|}{ EHCRIG (Q8) } \\
\cline { 2 - 6 } & $\begin{array}{l}\text { Project } \\
\text { supported }\end{array}$ & $\begin{array}{l}\text { Non-project } \\
\text { supported }\end{array}$ & $\begin{array}{l}\text { Project } \\
\text { supported }\end{array}$ & $\begin{array}{l}\text { Non-project } \\
\text { supported }\end{array}$ & $\begin{array}{l}\text { Project } \\
\text { supported }\end{array}$ \\
\hline $\mathrm{N}$ & 184 & 180 & 184 & 180 & 184 \\
\hline Mean rank & 216.87 & 147.37 & 244.68 & 118.93 & 257.67 \\
\hline Sum of ranks & 39903.50 & 26526.50 & 45022.00 & 21408.00 & 47412.00 \\
\hline Mann-Whitney U & 10236.50 & & 5118.00 & & 2728.00 \\
\hline Wilcoxon W & 22940.00 & & 21408.00 & & 191018.00 \\
\hline Z & -6.30 & & -11.40 & & -13.78 \\
\hline $\begin{array}{l}\text { Asymp. sig. (2- } \\
\text { tailed) }\end{array}$ & 0.001 & & 0.001 & & 0.001 \\
\hline
\end{tabular}

\section{Discussion}

In the last three decades - as with many low-income countries - several health reforms have been adopted and widely implemented to improve access to and quality of essential health services in Ethiopia. Some of the reforms are innovated, piloted, and scaled up through the technical and financial support of development partners. This comparative quantitative survey was conducted to investigate the relationship between performance management innovation and organizational culture, and excellence at primary healthcare entities in two administrative zones of Ethiopia. The study shows that the distribution of the study participants was not different by comparison group. In addition, the USAID Transform: Primary Health Care project supported primary health care units that managed to achieve the criteria for excellence in a much shorter span of time than non-supported facilities. The study elucidates evidence of increased highperforming primary healthcare units through implementing performance management innovations and through enhancing organizational culture.

The performance management innovation that was implemented in the target primary healthcare units is consistent with the recommended parameters of the Public Health Foundation [9]. The conceptual framework assumed the importance of exercising visible leadership in creating shared direction and sound work environments to mobilize and involve staff in reform initiatives. In this study, the study participants selected from project-supported facilities were more likely to be involved in creating high-performing primary healthcare units than their counterparts working in non-supported facilities. The results revealed a larger number of projects supported study participants engaged in performance improvements activities and in reporting on progress collaborative functions $(P<0.05)$ while equally participating in performance measurement activities $(P>0.05)$. This significant difference could be because of the direct expert support in the form of onsite coaching and mentoring, and regular follow-up of developed performance improvement projects. Furthermore, the adopted performance management innovation model-assisted primary healthcare units leaders to align routine activities with strategic priorities and improve the culture of quality at primary healthcare units [9].

The performance management innovation enhanced the leadership competencies of a hybrid of clinical and management professionals working in primary healthcare units [16] [17]. The intervention was designed to build organizational culture along with key performance indicators for primary healthcare unit excellence. The project supported the institutionalization of organizational culture at primary healthcare facilities in Ethiopia. Enhancing organizational culture is believed to promote the strategic direction, mission, and values among internal and external stakeholders. The findings of this research showed that the perception score of participants recruited from performance management innovation-supported facilities had a higher organizational culture score with a statistically significant positive difference when compared with scores of participants recruited from non-supported facilities. This finding was in line with Maithel et al., (2012) and Vainieri et al., (2019) report on the success of an organization with opportunities to learn and communicate norms among staff which had a positive effect on employee motivation and high organizational performances [18] [19].

Many developing counties have adopted and implemented minimum standards to increase the number of well-functioning and high-performing primary healthcare units [0]. The main purpose of working against minimum standards at primary healthcare units is to strengthen the health system and achieve global commitments in a shorter amount of time [21]. According to the results of this study, there is a high and statistically significant difference between the proportion of high-performing health facilities and project performance management innovation implementation statuses. Primary healthcare units achieved excellence after four and eight measurements for project-supported and non-supported facilities, respectively. This finding could be because of the close support of development partners.

\section{Strength and limitations}

This was an observational study that had both strengths and limitations. The strengths of this study include targeting two regional states in a decentralized health system and comparing performance management, organizational culture, and primary healthcare unit excellence by project support status. In addition, the investigators analyzed multiple sources of data to estimate the level of primary healthcare unit excellence in Ethiopia. However, like many observational 
studies, there are methodological limitations to claim a causality relationship. In addition, since performance management innovation and organizational culture were measured with interviewer-administered questionnaires, there might be social desirability bias.

\section{Conclusions}

The findings of this facility-based comparative study underscore a direct relationship between implementing performance management innovations to enhance organizational culture and excellence at primary healthcare unit excellence. Performance management innovation supported facilities that had higher organizational culture and primary healthcare unit excellence scores. Therefore, achieving UHC through excellence in primary healthcare facilities requires scaling-up performance management innovation interventions.

\section{Abbreviations}

EHCRIGs: Ethiopian Health Center Reform Implementation Guidelines; SD: standard deviation; SDGs: Sustainable Development Goals; SNNP: Southern Nations and Nationalities of Peoples; SPSS: Statistical Package for Social Science; USAID: United States Agency for International Development; UHC: universal health coverage

\section{Declarations}

\section{Acknowledgements}

The investigators are indebted to all participants for their cooperation during data collection.

\section{Funding}

Transform Primary Health Care Project is a United States Agency for International Development (USAID) funded health program under cooperative agreement number AID-663-A-17-00002. The program is implemented by a consortium of organizations which includes Pathfinder International, JSI Research \& Training Institute, Inc., EnCompass, Malaria Consortium, Abt Associate Inc., and Ethiopian Midwives Association in collaboration with local Government and Nongovernment partners. This technical comparative evaluation report is made possible by the generous support of the American people through USAID. The authors' views expressed in this technical report do not necessarily reflect the views of USAID or the United States Government.

\section{Availability of data and materials}

The datasets used and/or analyzed during the current study are available from the corresponding author on reasonable request.

\section{Authors' contribution}

The authors of this manuscript are WKH, EMG, AAA, AGS, AR, FS, MDA, \& BFD. All authors equally contributed to the conception and design of the study, fieldwork, data cleaning, analysis, and drafting of the manuscript. All authors have read and approved the final document. MDA: the corresponding author submitted the manuscript for publication.

\section{Ethics approval and consent to participate}

This study protocol was carried out in accordance with the Declaration of Helsinki and, and ethical clearance was granted from the JSI Research \& Training Institute, Inc. institutional review board (IRB) ref number IRB \#21-06E. Written informed consent was obtained from all research participants. The study participants were informed that they have the full right to participate or not to participate in the study and even they can quit responding in the middle of the interview if they desire to do so. To maintain the confidentiality of the collected data, anonymity was maintained throughout the research process. The study had no known risk and no payment was made to participants.

\section{Consent for publication}

Not Applicable

\section{Competing interests}

The authors declare that they have no competing interests

\section{Authors' information}

WKH: MPH, Health Systems Strengthening Officer at USAID Transform: Primary Health Care, JSI Research \& Training Institute Inc., Ambo, Ethiopia.

EMG: MPH, Health Systems Strengthening Officer at USAID Transform: Primary Health Care, JSI Research \& Training Institute Inc., Hawassa, Ethiopia.

AAA: MPH, Regional Technical Coordinator at USAID Transform: Primary Health Care, JSI Research \& Training Institute Inc., Hawassa, Ethiopia.

AGS: MPH, Regional Manager at USAID Transform: Primary Health Care, JSI Research \& Training Institute Inc., Hawassa, Ethiopia.

AR: MPH, Regional Manager at USAID Transform: Primary Health Care, JSI Research \& Training Institute Inc., Addis Ababa, Ethiopia. 
FS: MPH, Sub- regional Manager at USAID Transform: Primary Health Care, JSI Research \& Training Institute Inc., Ambo, Ethiopia.

MDA: Ph.D, Senior Health Systems Strengthening Advisor at USAID Transform: Primary Health Care, JSI Research \& Training Institute Inc., Addis Ababa, Ethiopia.

BFD: Ph.D, Deputy Chief of Party at USAID Transform: Primary Health Care, JSI Research \&Training Institute, Inc., Addis Ababa, Ethiopia.

\section{References}

1. Freeman T, Gesesew HA, Bambra C, Giugliani ER, Popay J, Sanders D, Macinko J, Musolino C, Baum F. Why do some countries do better or worse in life expectancy relative to income? An analysis of Brazil, Ethiopia, and the United States of America. International journal for equity in health. 2020 Dec;19(1):1-9.

2. United Nations. The Sustainable Development Goals Report 2019. Available online: https://unstats.un.org/sdgs/report/2019/The-SustainableDevelopment-Goals-Report-2019.pdf. (accessed on 29 September 2021)

3. Tedla TB. The impact of organizational culture on corporate performance (Doctoral dissertation, Walden University): 2016.

4. Watkins M. What is organizational culture? And why should we care. Harvard Business Review. 2013 May 15;15.

5. Ethiopian Federal Ministry of Health. Health Sector Transformation Plan II (2020- 2025). Addis Ababa: EFMoH; 2020.

6. Aguinis $\mathrm{H}$, Pierce CA. Enhancing the relevance of organizational behavior by embracing performance management research. Journal of Organizational Behavior: The International Journal of Industrial, Occupational and Organizational Psychology and Behavior. 2008 Jan;29(1):139-45.

7. Federal Democratic Republic of Ethiopia Ministry of Health. Ethiopian Health Centers Reform Implementation Guidelines. Addis Ababa: Ministry of Health of Ethiopia; 2016.

8. USAID Transform: Primary Health Care Project. Theory of Change in Practice 2017. Addis Ababa: USAID Transform: Primary Health Care; 2017.

9. Public Health Foundation. The Public Health Performance Management System Framework: Introduction \& Application to Public Health. Available from: 2012. http://www.phf.org/focusareas/performancemanagement/toolkit/Pages/PM_Toolkit_About_the_Performance_Management_Framework.aspx

10. Wahyuningsih SH, Sudiro A, Troena EA, Irawanto D. Analysis of organizational culture with Denison's model approach for international business competitiveness. Problems and perspectives in management. 2019(17, Iss. 1):142-51.

11. Ethiopian Public Health Institute (EPHI) [Ethiopia] and ICF. 2019. Ethiopia Mini Demographic and Health Survey 2019: Key Indicators. Rockville, Maryland, USA: EPHI and ICF. Available from: https://dhsprogram.com/pubs/pdf/PR120/PR120.pdf

12. Denison DR, Mishra AK. Toward a theory of organizational culture and effectiveness. Organization science. 1995 Apr;6(2):204-23.[13] Argaw MD, Desta $B F$. Examining governing board functions and health center performances during health system reform: a cross-sectional study in 4 regional states of Ethiopia. International journal of health policy and management. 2020 Dec 2.

13. Argaw MD, Desta BF, Bele TA, Ayne AD. Improved performance of district health systems through implementing health center clinical and administrative standards in the Amhara region of Ethiopia. BMC health services research. 2019 Dec;19(1):1-3.

14. Statistical Package for Social Science Inc. IBM SPSS Statistics Base 20. Chicago: SPSS Inc.; 2011.

15. Kyriakidou N, Aspasia G, George P, Anastasios S, Marios A. Leadership Development in Health Care: The Role of Clinical Leaders. Journal of Human Resource and Sustainability Studies. 2021;9(2):231-49.

16. Veronesi G, Kirkpatrick I, Vallascas F. Clinicians on the board: what difference does it make?. Social science \& medicine. 2013 Jan 1;77:147-55.

17. Maithel N, Chaubey DS, Gupta D. Impact of organization culture on employee motivation and job performance. International Journal of Research in Commerce \& Management. 2012;3:68-73.

18. Vainieri M, Ferre F, Giacomelli G, Nuti S. Explaining performance in health care: How and when top management competencies make the difference. Health care management review. 2019 Oct;44(4):306.

19. Mabuchi S, Alonge O, Tsugawa Y, Bennett S. Measuring management practices in primary health care facilities-development and validation of management practices scorecard in Nigeria. Global health action. 2020 Dec 31;13(1):1763078.

20. Al Rashidi B, Al Wahaibi AH, Mahomed O, Al Afifi Z, Al Awaidy S. Assessment of Key Performance Indicators of the Primary Health Care in Oman: A CrossSectional Observational Study. Journal of Primary Care \& Community Health. 2020 Aug;11:2150132720946953.

\section{Figures}




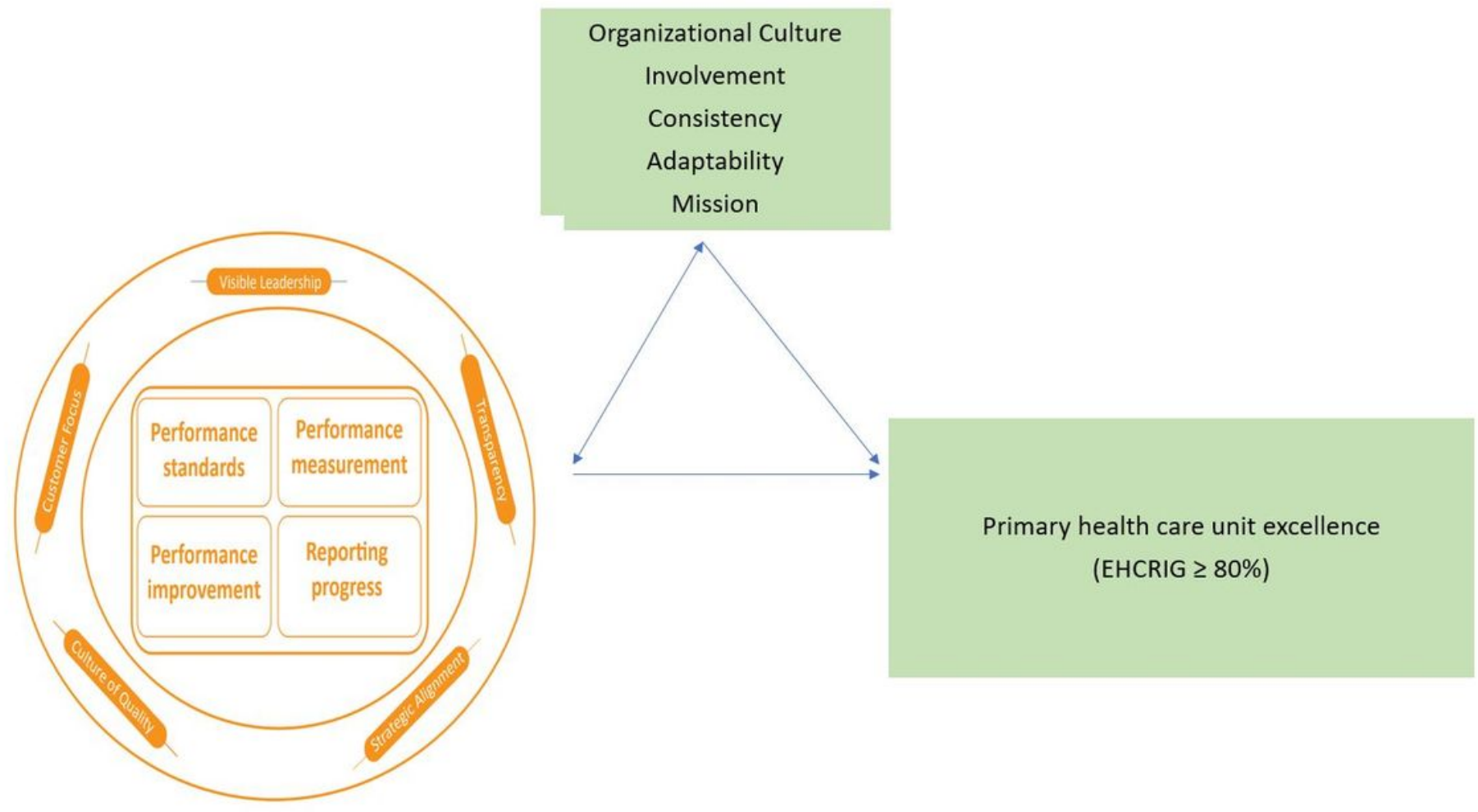

\section{Figure 1}

A conceptual framework developed to assess culture of excellence at primary healthcare units[10] A modified conceptual map developed to evaluate performance management innovations in two zones of Ethiopia. the framework illustrates the relationship of performance management, organizational culture, and primary health care unit excellence.

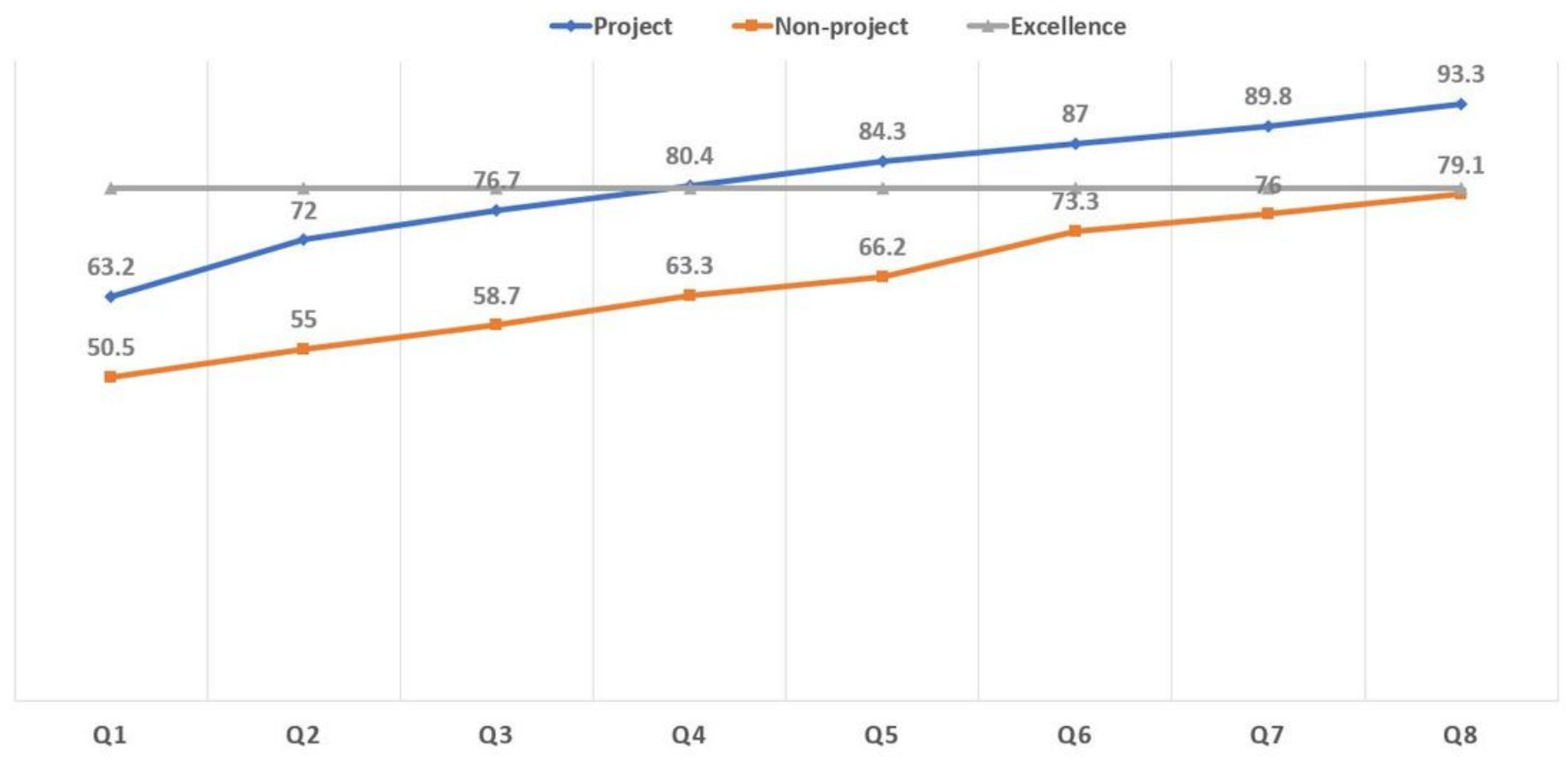

Figure 2 
Trends in primary health care unit excellence scores by project support status, August 2021 Line chart showing the criteria for primary health care unit excellence, and trends of achievement of project and non- project supported health facilities. 